\title{
Agent-Based Simulation Approach for Occupational Safety and Health Planning: A Case of Electroplating Facilities
}

\author{
Alexander Leiden ${ }^{1 *}$, Sebastian Thiede ${ }^{1}$, Christoph Herrmann ${ }^{1,2}$ \\ ${ }^{1}$ Chair of Sustainable Manufacturing and Life Cycle Engineering, Institute of Machine Tools and Production \\ Technology IWF, Technische Universität Braunschweig, Langer Kamp 19b, 38106 Braunschweig, Germany \\ *a.leiden@tu-braunschweig.de \\ ${ }^{2}$ Fraunhofer-Institut für for Surface Engineering and Thin Films IST, Bienroder Weg 54 e, \\ 38108 Braunschweig, Germany
}

SNE 30(4), 2020, 175-182, DOI: 10.11128/sne.30.tn.10537 Received: July 31, 2020 (Selected ASIM SPL 2019 Postconf. Publ.); Revised: Oct. 15, 2020; Accepted: Oct. 20, 2020 SNE - Simulation Notes Europe, ARGESIM Publisher Vienna ISSN Print 2305-9974, Online 2306-0271, www.sne-journal.org

Abstract. The current and future occupational safety and health $(\mathrm{OSH})$ regulations from various national and international regulations such as REACH ask for an increasing process transparency in the electroplating industry to monitor the OSH situation. Currently, the COVID-19-related situation of shopfloor workers also requires an increased transparency in contact tracking. Manufacturing system simulation is a promising approach in this context. To date, simulation models mainly focus on the processspecific technical, economic, or environmental aspects. Modelling the $\mathrm{OSH}$ of workers in plating industry is rarely the focus of these approaches. This paper shows an integrated simulation framework to model industrial automated electroplating lines and the interaction with involved shopfloor workers as part of a cyber-physical production system. Line-integrated pre- and post-treatment processes as cleaning and degreasing are considered as well as their effects on shopfloor workers. In a case study, different applications with regard to OSH are shown to demonstrate the applicability of the developed framework and the high adaptability to new challenges as social distancing during pandemics.

\section{Introduction}

Industrial electroplating processes are characterised by a high variety of process parameters. Due to dynamic interdependencies between and within the process steps, the relationship between process parameters, surface structure, and surface properties including energy and resource demand are not fully understood. Especially highly automated barrel plating lines are complex dynamic systems, consisting of subsystems that influence each other. Improvement measures in one subsystem often influence other subsystems, for example, the drag out from plating baths influences the following post-treatment baths.

Recently, in the EU, stringent requirements under the Registration, Evaluation, Authorisation and Restriction of Chemicals (REACH) regulation require increased process transparency and measures to increase the occupational safety and health (OSH) of the workers in electroplating facilities [1]. Today, in most countries OSH authorities restrict the use of widely used electroplating substances if no sufficient data regarding the OSH situation are available. Further, recent challenges such as the COVID-19 pandemic require a fast adaption for production processes and OSH planning as plating lines require shopfloor workers.

Currently, these OSH aspects are rarely considered in simulation models for planning and operation of electroplating facilities. The high complexity makes it difficult to rate the effects of a single measure on the overall OSH situation. Especially for OSH measures, the interdependencies to process parameter are often not considered in the planning phase nor during operations. 
To support higher process transparency, an integrated multiscale and multilevel simulation approach has been developed. The simulation is used as part of the cyber system and embedded in the cyber-physical production system (CPPS) that is the basis for a comprehensive decision support system. This approach significantly increases the process transparency allowing for evaluating the OSH situation a priori in the planning phase of an electroplating line as well as during operation. OSH planning benefits significantly from a simulation approach, as changes during operation are often very costly or even not realisable in a productive manufacturing environment. Further, specific exposure measurements only consider static production situations during the measurement. These measurements do not consider the dynamic character of electroplating process lines such as changing process parameters.

\section{Background}

\subsection{Automated Electroplating Process Chains}

Automated rack and barrel plating lines enable plating high volumes of small-to-medium-sized parts at high quality and reproducibility. Figure 1 provides a schematic overview of an automated industrial rack electroplating line. Parts are loaded and unloaded manually at the beginning and at the end of the plating line. In the plating facility, a set of tanks, filled with pre-treatment, plating, and post-treatment fluids, is aligned in one or multiple lines. A rail-mounted hoist (RMH) system transports the barrels, or more generally the carriers, between the single tanks starting from pre-treatment processes as cleaning and degreasing, through the electroplating process to post-treatment processes as rinsing or passivation [2]. Peripheral systems as exhaust air systems support the process baths and ensure that workplace concentrations are not exceeded [3; 4].

Although electroplating lines are highly automated processes, shopfloor workers are required for loading and unloading parts for the maintenance and cleaning of tanks, fluids, and periphal devices. Electroplating lines for small lots of big parts that require high quality coating are often less automated and also require workers for shifting the parts between the tanks. In this case, also groups of workers can be necessary to manoeuvre the parts with a crane through the electroplating line.

Typically, the carriers follow the direction of the plating line. However, backwards and lateral movements to parallel tank lines are required due to space restrictions and in order to enhance the flexibility. Further, storage spaces can be included to store carriers between processing steps to enhance the productivity of the plating system.

\subsection{Occupational Safety and Health for Electroplating Processes}

Especially the use of hazardous chemicals in the electroplating industry catched the interest of OSH authorities and organisations in nearly all countries over the world, starting from international organisations such as the International Labour Organisation (ILO), which published International Hazard Datasheets on Occupation for electroplater [5], to more specific European Regulations from the European Chemicals Agency (ECHA), which restrict the use of specific plating chemicals by placing them on the authorisation list [1].

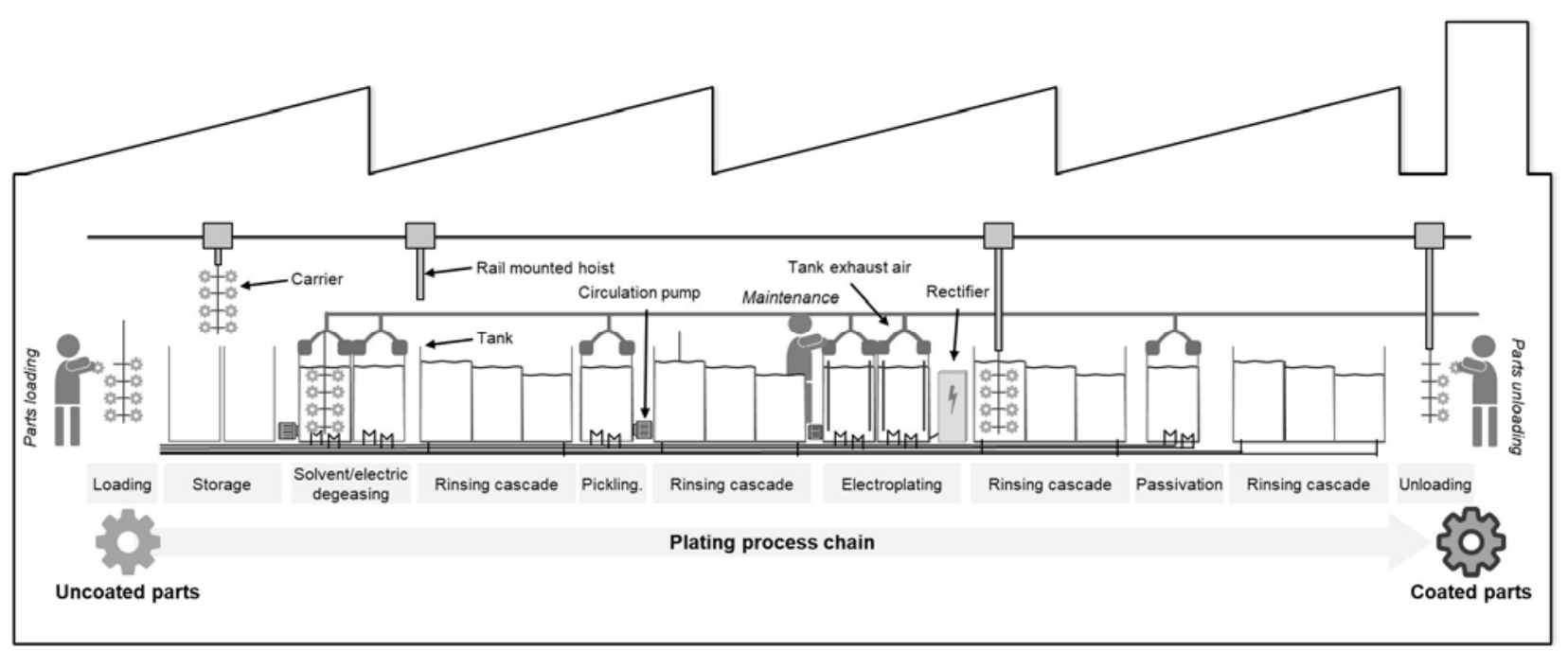

Figure 1: Overview of elements of an electroplating line. 
Also in the United States [6] and in China the ministry of environmental protection put relevant plating chemicals such as hexavalent chromium (CrVI) on the first batch of the priority control chemicals list [7]. A commonality of all these regulations is the requirement for a higher transparency to rate to the risks for the workers on the shop floor in the electroplating facility.

Aside the risks from chemicals, in pandemic also social distancing measures become necessary to keep the number of cases low [8]. A flexible manufacturing systems simulation with focus on the shop floor workers allows for rating the effects of measures minimizing the infection risks of shop floor workers.

\subsection{Simulation of Manufacturing Systems}

Electroplating combines discrete and continuous processes. The workpieces are typically stored in barrels or racks and go through the cleaning, rinsing, and plating processes, which have a discrete character, in batch mode. Fluids for cleaning, rinsing, plating, and posttreatment flow continuously through the system. [9] Therefore, a combined discrete and continuous simulation approach within an agent-based simulation environment is proposed as simulation paradigm.

Today, most available simulation tools for manufacturing systems are capable to model discrete manufacturing systems focussing on material and product flows. Within the last decade the simulation of energy flows has been included [10]. Hesselbach et al. [11] introduce a model-coupling approach to consider the production and technical building system within one environment. The approach by Thiede [12] is generic and supports simulating many different production systems, but mainly focuses on the energy demand. Bleicher et al. [13] developed a simulation with a focus on the energy demand simulation for machining processes and also included the energy and building system into their simulation.

The approach by Eisele [14] focuses on the energy demand of machine tools. Schönemann [15] developed an approach allowing co-simulation applied to battery production systems. Kurle [16] partially included electroplating processes into his approach, but mainly focusses on the heat flows in the production system. Xu et al. [17] model the resource flows in electroplating and rinsing systems in detail, but neglect the energy demand and further systems of the plating line. This detailed approach also allows for simulating only one specific product.
Modelling workers in production engineering simulation environment is already described in the German VDI guidelines 3633, part 6 [18] and 4499, part 5 [19]. The guideline 4499 part 5 is focussing on ergonomic representation of humans in the digital factory, while guideline 3633 part 6 also describes the use of simulation models for planning purposes.

In difference to existing approaches, the developed simulation focusses on automated plating lines addressing the specific characteristics. Dedicated models for electroplating lines and shop floor workers are developed. New innovative visualisations are integrated to analyse the OSH situation.

\section{Framework for Manufacturing Systems Simulation of Electroplating Lines}

CPPS contain a physical and a cyber system that are interlinked with data acquisition, feedback, and control systems [20].

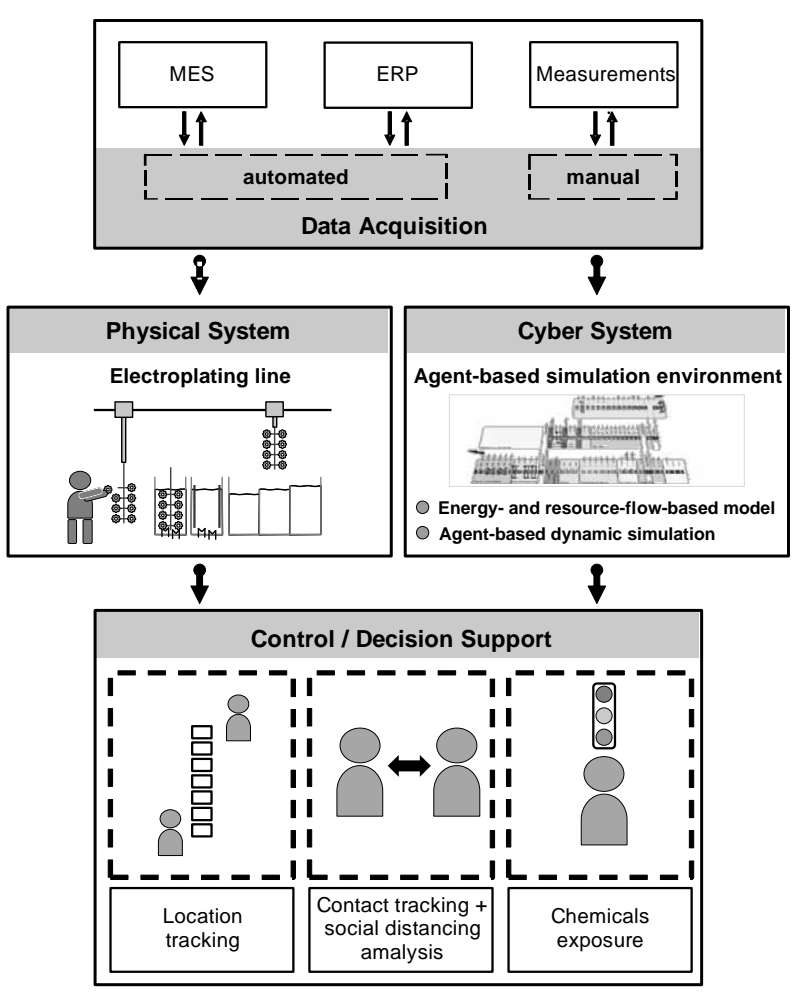

Figure 2: Integration of simulation as cyber system into a CPPS. 
For this study, an automated barrel electroplating line is used as physical system and the simulation as cyber system (Figure 2). Relevant data are acquired from the electroplating line and used as input for the simulation. The simulation is the basis for a comprehensive decision support system and allows for predicting the future behaviour of the plating line.

Compared to a stand-alone simulation, the integration of the simulation in the CPPS enables a comprehensive decision support for multi-criterial planning and control of the electroplating line, using live data from the electroplating line.

For a CPPS realisation, an efficient data acquisition from the physical system is decisive. Already available sensors and data are used and enhanced by additional manual measurements. From the Manufacturing Execution System (MES), the pending production batches with their characteristics and the process chains are transmitted. At the same time, product-specific data are retrieved from the Enterprise Resource Planning System (ERP). MES and ERP were connected with file-based interfaces to the simulation to enable an automated data transfer. Additionally, electrical power, chemicals, and air emissions concentration measurements were conducted to build an electricity and resource flow model for the plating line. Compared to the installation of various sensors for electricity and air emission measurements, this approach is more efficient, and no extensive additional sensor network is required.

The acquired data are the basis for the parametrisation of the agent-based simulation. Figure 3 provides an overview of the simulation model. Seven state-based multiparameter models were developed to build up a framework for the simulation model. Each model represents an agent type and can be multiplied to build the whole plating line.

The agent type product represents the product to be plated and contains the product's properties as surface, volume, weight, material, or drag-out behaviour. These properties are required to calculate the energy demand and the drag-out behaviour of specific products. Carriers are filled with a defined number of products and are used to transport the products to different tanks. $R M H s$ transport the carriers between the tanks. The operation area of RMHs is restricted and contains a state-based model, which also allows for modelling the energy demand. The RMHs can be controlled by commands from the MES system or by algorithms within the simulation environment.

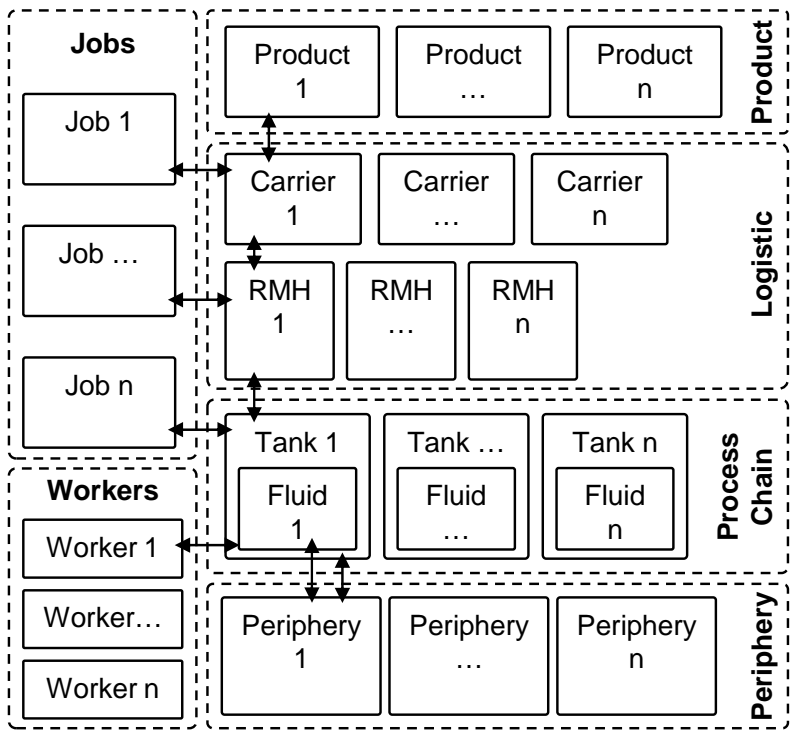

Figure 3: Structure of the simulation model [21;22].

The agent type tank represents the fluid tanks to build the plating process chain. Again, a state-based model represents the current situation (empty, occupied, in process, and waiting for $\mathrm{RMH}$ ) and is the basis for the energy model of the tank. The energy demand of local energy consumers, for example the drives for rotating the carriers during plating or rectifiers for the electroplating process, are modelled within this agent. Tanks can be filled with a fluid or remain empty in case a tank is used as storage space. It is possible to use one fluid for multiple tanks in case the tanks are connected with a piping system. Additional periphery can be connected to the fluid (e.g., in case of circulation pumps for multiple baths), to multiple tanks (e.g., in case of tank-state-controlled exhaust air systems) or depending on factors outside of the process chain (e.g., in case of cooling units for control systems).

The agent type job contains all relevant information to proceed a product through the plating process chain, such as process steps, times and parameters. This is the basis for a simulation run, and this agent type receives job data from the MES. The agent type worker represents people working within the plating line. Each worker has a specific order of tasks, which are related to OSH data. In chromium plating lines, the CrVI air emissions are in the focus of the OSH authorities and should be monitored.

In Table 1, an exemplary list of task is shown that contains the duration of the tasks and the exposure during this task. The available tasks and the corresponding CrVI exposure values are stored in a database, so that each worker can be configured with its specific tasks during a shift. 
Figure 3 also provides an overview on agent communication and interaction during the models runtime.

For control and decision support, three specific amending decision support modules with model-based key performance indicators and visualisations were developed. These are introduced with industrial examples in the following sections:

- Workers location modelling on shop floor

- Workers contacts and social distancing modelling

- Hazardous chemicals exposure modelling

\begin{tabular}{llcr}
\hline ID & Task & Duration & OM exposure \\
\hline 1 & Loading Parts & $60 \mathrm{~min}$ & 0.1 \\
\hline 2 & Taking samples & $20 \mathrm{~min}$ & 1 \\
\hline 3 & Refilling Chemicals & $10 \mathrm{~min}$ & 4 \\
\hline$\ldots$ & $\ldots$ & $\ldots$ & $\ldots$ \\
\hline
\end{tabular}

Table 1: Extract from work schedule with example emission data.

\section{Industrial Case Study}

The presented framework was applied to the example of a small-to-medium-sized company running an electroplating facility for small-to-medium-sized automotive parts. Six active plating baths are available as well as all the required pre- and post-treatment baths to fulfil the requirements from the automotive industry. In the following three subsections, the three developed applications for OSH planning are presented.

\subsection{Workers-Locations Modelling}

For effective measures towards reducing OSH risks, it is required to know the work places that are associated with $\mathrm{OSH}$ risk and the paths between them depending on their tasks. Also, for human factors and ergonomics planning, the lengths of walking paths and working time at specific work places on the shop floor are required. Tracking the location of workers with technical solutions, such as GPS or local radio-based systems, is associated with high effort and cost as well as privacy concerns. Tracking the workers in a modelbased environment reduces the technical effort significantly and does not cause privacy concerns, as the workers can be anonymsised in case of a-priori simulation. During the application process, also the workers' union should be involved to consider the perspective of the employees for specific simulation runs.

The integrated evaluation module in the simulation with visualisation towards a decision support can be implemented at low effort.

Based on the simulation for analysing and visualising of paths in operation rooms from Koshkenar et al. [23], a visualisation based on heat maps has been developed. To visualise the employees' workplaces and paths during a shift, a heat map is projected on the shop floor layout.

Figure 4 shows the plating line layout with the heat map, which indicates the number of workers per square meter. The two red points at the upper left side indicate a high employee density in an uncritical area, where the controls of the line are located and parts are unloaded. In the critical area (dosing tanks and plating baths at the right side) employees stay for a relatively short duration. This visualisation enables an easy detection of areas with a high worker density and the effect of different task schedules for the workers.

Beside the visualisation, also a quantitative analysis of the walked paths is possible. In this specific scenario, the first worker with changing jobs walks $800 \mathrm{~m}$ over an 8 -hour shift while the second walks only $29 \mathrm{~m}$ and the third worker $73 \mathrm{~m}$. The reason is that the first and the second worker focus on loading and unloading parts, while the first also conducts various maintenance tasks in the plating line. However, all walked paths are uncritical from an OSH perspective, especially compared to other manufacturing areas such as automotive assembly lines.

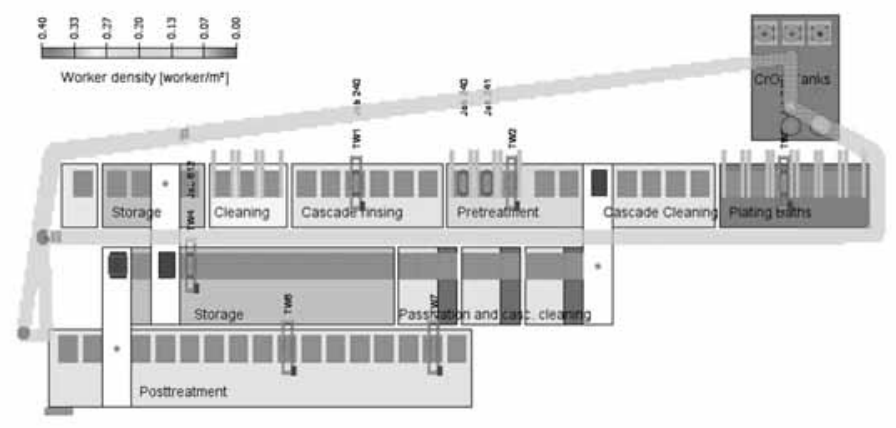

Figure 4: Shop floor heat map based on worker location 


\subsection{Workers Contacts Modelling}

One advantage of the agent-based simulation approach is its high adaptability to new situations such as the unexpected pandemic COVID-19. With adaptations, the simulation can be used to estimate the contact durations between workers, and provide measures towards social distancing in order to tackle the COVID-19 pandemics.

To keep the number of infections low, it is required to keep the number and duration of contacts on the shop floor level as low as possible.

The worker location tracking mechanism from the previous chapter is extended by a parameteriseable social distance circle (typically $1.5 \mathrm{~m}$ ). This circle is checked every second for other workers, respectively agents. If another worker is within this circle, a state-chart-based mechanism triggers the visualisation and statistics module.

Figure 5 shows the $3 \mathrm{D}$ visualisation with three workers whose social distancing circle colour depends on other workers located within this circle. In the visualization on the screen, green indicates that the worker is save with no other worker within his social distancing circle, and red indicates that another worker is within the social distancing circle.
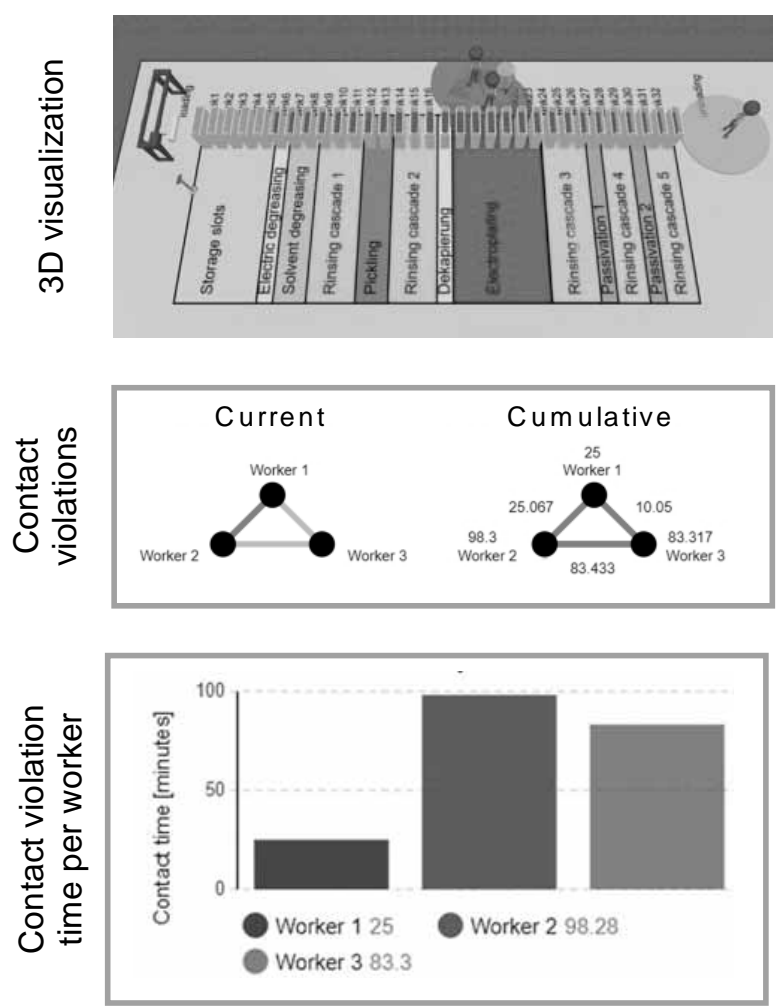

Figure 5: 3D Visualisation of social distancing in plating line.
A dashboard visualises the current and cumulative contact situation. Beside a classic bar diagram that indicates the contact length to other workers, a graph-based visualisation has been developed. Workers are visualised as vertices and the contact between them as edge. The colour of the edges depends on the contact intensity between two workers.

Table 2 summarises the contact times between three workers during an 8-hour shift from two scenarios. In the first scenario, Worker 1 and 3 work in parallel for 75 minutes during a shift.

By adopting their task schedules, their contacts could be prevented. Worker 1 and 2 meet for 2 seconds while walking to their next workplace. It has been assumed that this short duration is uncritical. Thus, no changes are required.

\begin{tabular}{|c|c|c|c|c|}
\hline & \multicolumn{2}{|c|}{ Scenario 1} & \multicolumn{2}{|c|}{ Scenario 2} \\
\hline & Worker 1 & Worker 2 & Worker 1 & Worker 2 \\
\hline Worker 1 & - & - & - & - \\
\hline Worker 2 & 75 minutes & - & $\begin{array}{l}\text { no } \\
\text { contact }\end{array}$ & - \\
\hline Worker 3 & 2 seconds & $\begin{array}{l}\text { No } \\
\text { contact }\end{array}$ & 2 seconds & $\begin{array}{l}\text { no } \\
\text { contact }\end{array}$ \\
\hline
\end{tabular}

Table 2: Evaluation of social distancing violations.

\subsection{Hazardous Chemicals Exposure Modelling}

Recent updates of the REACH regulation ask for a higher process transparency for the use of critical substances, in particular chromium trioxide in the electroplating industry. The developed simulation approach is used to calculate the workers' OSH situation based on their job profile and the current process parameters in the plating line. This allows for calculating the workplace exposure to a worker during single tasks based on surrogate models from the advanced reach tool [24]. The simulation tool can be used for comparing different scenarios a priori without further measurements.

In Table 3, the average and current emission loads for specific work schedules of three workers are shown. The average CrVI emissions are below the limit of $5 \mu \mathrm{g} / \mathrm{m}^{3}$ during an 8-hour shift. For Worker 2 and 3, the limits are exceeded for short durations, so that measures to lower the peak loads are required. In this specific case, the use of respirators for adding hexavalent chromium to the plating bath is advised. 


\begin{tabular}{lrr}
\hline & Average & Max \\
\hline Worker 1 & 0.756 & 5.0 \\
\hline Worker 2 & 3.689 & 16.1 \\
\hline Worker 3 & 0.075 & 16.0 \\
\hline
\end{tabular}

Table 3: CrVl emission load in $\mu \mathrm{g} / \mathrm{m}^{3}$.

Different measures can be applied to improve the workers' OSH situation. Beside personal protective equipment, operations close to the plating baths and dosing tanks should be avoided. In addition, job rotation can be a measure to improve the situation. The simulation approach can be used for the validation of these improvement measures.

To increase the awareness of decision makers in production planning, innovative ways to visualise the workers' OSH situation were developed. For the 3D simulation visualisation, the current situation of a worker is indicated by coloured balls above their head (Figure 6).

On the original screen, green indicates no critical exposure, yellow an exposure close to the critical value (4 to $\left.5 \mu \mathrm{g} / \mathrm{m}^{3}\right)$, and red a critical exposure $\left(>5 \mu \mathrm{g} / \mathrm{m}^{3}\right)$ that requires immediate measures.

As the air emissions exposure highly depends on the location of a worker during a shift, a visualisation to map their location during a shift (as shown in Figure 4) will help to prioritise measures.
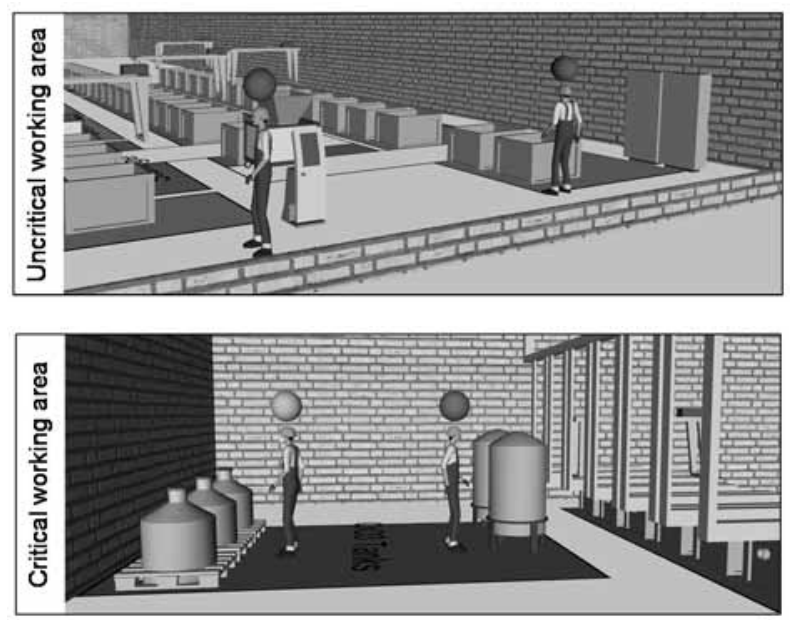

Figure 6: Visualisation of occupational workplace OSH situation.

\section{Conclusion, Discussion, and Outlook}

A framework to use an agent-based simulation with focus on OSH applications as part of a CPPS for automated industrial electroplating lines has been introduced. The case study showed the applicability and the benefits from using a simulation approach for studying the OSH situation. Three specific decision support modules increase the transparency regarding the OSH situation significantly and provide the basis for further development of the simulation framework.

For future steps, especially the results from the hazardous chemicals exposure modelling should be verified with temporal measurements. As a further step, detailed indoor air emission models could be integrated to model the spread of aerosols containing hazardous chemicals or viruses.

The CPPS approach can be the basis for further surface treatment processes such as chemical or electrophoretic coating. From a production engineering simulation perspective, the general plating layout is similar and mainly the model's details need to be adjusted. In addition, the generic character of the models is transferable to production processes from other industry sectors.

\section{Acknowledgement}

The research results are part of the project "SynARCO Synergetische Analyse und Verbesserung von Ressourceneffizienz und Chemikalienmanagement in der Oberflächentechnik“ (grant ID: 34848/01), sponsored by the Deutsche Bundesstiftung Umwelt. The authors thank the cooperation partner eiffo eG for providing the industrial data for the case study.

\section{References}

[1] European Chemicals Agency. Substance information: Chromium trioxide; http://echa.europa.eu/de/ substanceinformation/-/substanceinfo/100.014.189, accessed 02.05.2019.

[2] Schmid SR, Jeswiet J. Surface treatment and tribological considerations. In: Sutherland JW, Dornfeld DA, Linke BS, editors. Energy Efficient Manufacturing. Hoboken: John Wiley \& Sons; 2018. 169-195. 
[3] Ritzdorf T. Manufacturing tools. In Schlesinger M, Paunovic M, editors. Modern Electroplating. Hoboken: John Wiley \& Sons; 2010.

[4] Hofmann, H, Spindler J. Verfahren in der Beschichtungs- und Oberflächentechnik. 2nd edition. München, Wien: Hanser; 2010. 284 p.

[5] International Labour Organisation. International hazard datasheets on occupation: Electroplater. https://www.ilo. org/wcmsp5/groups/public/---ed_protect/---protrav/--safework/documents/publication/wcms_193163.pdf, accessed 24.07.2020.

[6] Baral A, Engelken RD. Chromium-based regulations and greening in metal finishing industries in the USA. Environmental Science \& Policy; 2002; 5(2). 121-133. doi: 10.1016/S1462-9011(02)00028-X

[7] Chemical Inspection and Regulation Service. China MEP published list of priority chemicals. http://www. cirs-reach.com/news-and-articles/China-MEP-PublishedList-of-Priority-Chemicals.html, accessed 07.08.2020.

[8] Maier BF, Brockmann D. Effective containment explains subexponential growth in recent confirmed COVID-19 cases in China. Science; 2020; 368(6492). 742-746. doi: 10.1126/science.abb4557

[9] Kuntay I, Xu Q, Uygun K, Huang Y. Environmental conscious hoist scheduling for electroplating facilities. Chemical Engineering Communications; 2006; 193(3). 273-292. doi: 10.1080/009864490949125

[10] Duflou JR, Sutherland J W, Dornfeld D, Herrmann C, Jeswiet J, Kara $\mathrm{S}$ et al. Towards energy and resource efficient manufacturing. CIRP Annals - Manufacturing Technology; 2012; 61(2). 587-609. doi: 10.1016/j.cirp. 2012.05.002

[11] Hesselbach J, Herrmann C, Detzer R, Martin L, Thiede S, Lüdemann B. Energy efficiency through optimized coordination of production and technical building services. In Kaebernick H, editor. Applying life cylce knowledge to engineering solutions, Mar 2008; Sydney. Sydney: UNSW. 624-628.

[12] Thiede S. Energy efficiency in manufacturing systems. Berlin: Springer; 2012. 198 p.

[13] Bleicher F, Duer F, Leobner I, Kovacic I, Heinzl B, Kastner W. Co-simulation environment for optimizing energy efficiency in production systems. CIRP Annals Manufacturing Technology; 2014; 63(1). 441-444. doi: $10.1016 /$ j.cirp.2014.03.122
[14] Eisele C. Simulationsgestützte Optimierung des elektrischen Energiebedarfs spanender Werkzeugmaschinen. Herzogenrath: Shaker; 2014. 179 p.

[15] Schönemann M. Multiscale simulation approach for battery production systems. Cham: Springer; 2017. $176 \mathrm{p}$.

[16] Kurle D. Integrated planning of heat flows in production systems. Cham: Springer; 2018. 245 p.

[17] Xu Q, Telukdarie A, Lou HH, Huang Y. Integrated electroplating system modeling and simulation for near zero discharge of chemicals and metals. Ind. Eng. Chem. Res.; 2005; 44(7). 2156-2164. doi: 10.1021/ie0495067

[18] VDI 3633 Part 6. Simulation von Logistik-, Materialfluss und Produktionssystemen - Abbildung des Personals in Simulationsmodellen. Berlin: Beuth. 2001.

[19] VDI 4499 Part 4. Digital factory. Ergonomic representation of humans in the digital factory. Berlin: Beuth. 2015.

[20] Thiede S, Juraschek M, Herrmann C. Implementing cyber-physical production systems in learning factories. Procedia CIRP; 2016; 54(1). 7-12. doi: 10.1016/j.procir. 2016.04.098

[21] Leiden A, Thiede S, Herrmann C. Agent-based simulation for multi-criterial planning and control of automated electroplating lines. In: Putz M, Schlegel A, editors. Simulation in Produktion and Logistik 2019. Auerbach: Wissenschaftliche Scripten; 2019. 111-120.

[22] Leiden A, Herrmann C, Thiede S. Cyber-physical production system approach for energy and resource efficient planning and operation of plating process chains. Journal of Cleaner Production. In Press. doi: 10.1016/j.jclepro.2020.125160

[23] Khoshkenar A, Taaffe K, Muhs M, Fredendall L, Ferrand Y, Joseph A, San D. Simulation-based design and traffic flow improvements in the operating room. In: Chan WK, D'Ambrogio A, Zacharewicz G, Mustafee N, Wainer G, Page EH, editors. 2017 Winter Simulation Conference. Piscataway: IEEE; 2017. 2975-2983. doi: 10.1109/WSC.2017.8248019

[24] McNally K, Warren N, Fransman W, Entink RK, Schinkel J, van Tongeren M, Cherrie W, Kromhout H, Schneider T, Tielemans E. Advanced REACH Tool: A Bayesian model for occupational exposure assessment. The Annals of occupational hygiene; 2014; 58(5). 551565. doi: 10.1093/annhyg/meu017 